\title{
Students' group work strategies in source-based writing assignments
}

Eero Sormunen*)

School of Information Sciences, FIN-33014 University of Tampere, Finland

eero.sormunen@uta.fi

Mikko Tanni

School of Information Sciences, FIN-33014 University of Tampere, Finland mikko.tanni@uta.fi

Tuulikki Alamettälä

School of Information Sciences, FIN-33014 University of Tampere, Finland tuulikki.alamettala@uta.fi

Jannica Heinström

Research Collegium, FIN-33014 University of Tampere, Finland

jheinstr@abo.fi

${ }^{*}$ ) corresponding author

Note. This is a copy of a manuscript accepted for publication in Journal of the American Society for Information Science and Technology. Please do not cite this version but the final one published by JASIST. 


\section{Eero Sormunen}

\section{Abstract}

Source-based writing assignments conducted by groups of students are a common learning task used in information literacy instruction. The fundamental assumption in group assignments is that students' collaboration substantially enhances their learning. The present study focused on the group work strategies adopted by upper secondary school students in source-based writing assignments. Seventeen groups authored Wikipedia or Wikipedia-style articles and were interviewed during and after the assignment. The interviews were analyzed to identify the key activities which the students undertook, the ways the group work was conducted in these activities and how the students justified their choice of group work strategies.

Group work strategies were analyzed in six activities: planning, searching, assessing sources, reading, writing and editing. The students used two cooperative strategies: delegation and division of work, and two collaborative strategies: pair and group collaboration. Division of work into independently conducted parts was the most popular group work strategy. Also group collaboration, where students worked together to complete an activity, was commonly applied. Division of work was justified by efficiency in completing the project and by ease of control in the fair division of contributions. The motivation behind collaboration was related to quality issues and shared responsibility. The authors suggest that the present designs of learning tasks lead students to avoid collaboration increasing the risk of low learning outcomes in information literacy instruction.

\section{Introduction}

Our views on learning are informed by competing knowledge-acquisition and participation metaphors based on theories emphasizing either the individual or the social aspects of learning. Present pedagogies of schooling build on the knowledge-acquisition metaphor where motivation, cognition, rational thinking and knowledge of an individual are in the focus of teaching. (Hakkarainen, 2009; Sfard, 1998.) Collaboration brings many benefits to the knowledge building process: for example, joint efforts to complete a learning assignment encourages students to discuss the problem in hand from various viewpoints, to activate and share relevant knowledge about the problem, to generate ideas on how to solve the problem, and to search for and negotiate the use of information sources. Through constant discussion and interaction, students gain insights that would be difficult for them to achieve on their own (Stahl, 2006). 


\section{Eero Sormunen}

In practice the division between the camps is not clear cut. Schools have gradually adopted some aspects of collaborative learning into their work methods. Group work assignments are also common in the school's information literacy education (see e.g. Chu, Chow, Tse, \& Kuhlthau, 2008; Chu, Tse, \& Chow, 2011; Kuiper, Volman, \& Terwel, 2005; Limberg, 1997, 1998; Sormunen \& Lehtiö, 2011; van Aalst, Hing, May, \& Yan, 2007). Kuhlthau, Maniotes, \& Caspari $(2007,35-45)$ have introduced a model called inquiry circles for integrating group work into the Guide Inquiry framework for information literacy instruction. However, most studies on IL instruction do not specify pedagogical ideas on which group work is based. They tell little about students' collaborative behaviors in group assignments except the study of Limberg $(1997,1998)$.

This paper reports a naturalistic inquiry on how student groups at an upper secondary school collaborated in a sourcebased writing assignment intended to develop their information literacy practices. The study was motivated by the findings of our earlier study (Sormunen, Lehtiö, \& Heinström, 2011) where we found that many student teams split group work assignments into individually conducted projects coordinated loosely or not at all. This behavioral pattern seemed to ruin the basic idea of group assignments.

Our goal was to reveal the ways in which students organize their group work when they have a relatively free choice to work as they like. We adopted a task-based approach where the task in focus was the source-based writing assignment which required the students in teams to write an encyclopedic text according to Wikipedia standards. We focused on teams' strategies to work in different activities of the assignment such as information seeking and evaluation, reading of sources, planning the content and writing the required text. We also wished to reveal whether we could categorize groups on the basis of their overall collaboration patterns. Further, we wanted to find out how students justify their group work strategies in different activities.

The paper is organized as follows: we begin by introducing our theoretical framework, which is followed by a review of related research. Then we present our research questions, and report our methods for data collection and analysis. We continue by presenting the findings and close by discussing them and presenting conclusions.

\section{Theoretical framework}

The overall framework of our research is bound to knowledge building pedagogy (Scardamalia \& Bereiter, 2006) and to the task-based approach of information retrieval and seeking (Ingwersen \& Järvelin, 2005; Vakkari, 2003). The knowledge building pedagogy is an alluring perspective to learning because it aims to create a balance between 


\section{Eero Sormunen}

individual and social aspects of learning. We argue that it is fruitful to conceptualize learning assignments as tasks since the design of learning tasks is the teacher's primary Instrument in directing students to practice appropriate forms of information seeking and use (cf. Limberg, 2007).

\section{Knowledge-building pedagogy}

Knowledge- building pedagogy was developed by scholars in computer supported collaborative learning (CSCL) (see (Bereiter, 2002; Hakkarainen, 2009; Scardamalia \& Bereiter, 2006). Knowledge building pedagogy advocates a "shift from treating students as learners and inquirers to treating them as members of a knowledge building community". Interestingly, the authors associate this principle with the Internet age and state that the Internet "... becomes the first realistic means for students to connect with civilization-wide knowledge building and to make their classroom work part of it". The very basic premise is that the focus is moved from the individual student to advancing the state of the classroom community. (Scardamalia \& Bereiter, 2006.)

Scardamalia \& Bereiter (2006) list several aspects of the knowledge building pedagogy where it differs from the present school pedagogy:

- Students are engaged in the collaborative creation of "epistemic artifacts" which may be purely conceptual, such as theories and abstract models, or "epistemic things" such as concrete models or experimental set-ups.

- The goal of knowledge building is more about the improvement of ideas than adopting "pre-existing truths". The improvement of ideas in the classroom community is, however, intended to lead towards justified views of the world.

- Similar to inquiry learning (e.g. inquiry-, project-, or problem-based learning) knowledge is seen as a broad notion called knowledge of [something] which roughly covers both declarative and procedural knowledge. Knowledge [of] is structured around problems rather than topics. Driving questions are a typical trigger in improving ideas.

- Knowledge building discourse is a key tool in enhancing the state of knowledge of the community. Students have to engage in three commitments in discourse: 1) to progress, 2) to seek common understanding, and 3) to expand the base of accepted facts. 


\section{Eero Sormunen}

- Constructive use of first-hand experience, secondary sources and authoritative information, and judging their quality are an essential part of knowledge building discourse.

Stahl's (2000) model characterizes how the personal and the social interact in the process of knowledge building (Fig. 1). The elements on the left illustrate the cycle of personal understanding. The cycle starts from the tacit preunderstanding on which our beliefs of the world are based. In some activities we become aware of a mismatch between our beliefs and something else in the world. The network of meanings by which we make sense of our world must be mended. We may "repair" our understanding by reinterpreting our meaning structures, for example, by using a cultural artifact such as a document.

[Fig. 1 about here]

The theory of knowledge building pedagogy (Scardamalia \& Bereiter, 2006) and the model of individual and social knowledge building (Stahl, 2000) inform us of some important characteristics of collaborative learning tasks. The developers of cooperative learning pedagogy introduced similar ideas already in the 1970 s (see Johnson \& Johnson, 1991; Slavin, 1983). The aim of cooperation is to improve the individual's motivation and learning outcomes through group work where different roles or task specialization can be assigned to team members. Textbooks on the theory and practice of cooperative learning describe a number of methods for group work in schools (see Gillies, 2007; Johnson \& Johnson, 1991; Sharan \& Sharan, 1992; Slavin, 1983).

Dillenbourg (1999) makes a distinction between collaborative and cooperative learning. In collaboration, partners work together from start to finish. In cooperation, the task is split into subtasks which are completed individually so that at the end, the partial results are assembled into the final output. Both Roschelle \& Teasley (1995) and Stahl, Koschmann, \& Suthers (2006) point out that cooperation and collaboration lead to different learning processes: in the former, learning is accomplished solely by individuals in separated processes while, in the latter, learning occurs socially as a shared building of knowledge. In practice, cooperative and collaborative approaches to group work overlap since the various models developed in the cooperative pedagogy possess elements of social knowledge building (e.g. Gillies, 2007; Huber \& Huber, 2008).

In this paper, we define that students collaborate when they work together as a group to complete an activity, and cooperate when individual students adopt different roles or tasks in completing an activity. 


\section{Eero Sormunen}

\section{Task-based approach to information seeking and use}

A task can be defined as an activity to be performed to accomplish a goal. The performance of a task includes physical and cognitive actions. The process consists of a series of subtasks and results in a meaningful (end-)product. The study of tasks is motivated by the view that our understanding of information searching is only partial if we neglect the task as the trigger of searching. (Vakkari, 2003.) The goal of research has typically been to reveal how variation in task variables (e.g. task complexity - Byström \& Järvelin, 1995; Vakkari, 1999) explains variation in information seeking and retrieval variables.

Limberg (2007) argues that although tasks are commonly interpreted as work-related, learning assignments can be regarded as a sub-category of tasks. She suggests there are particular conditions that shape learning-related information seeking. Assignments are imposed on students by the teacher and the goals of the assignment are related to learning outcomes of topical contents and abilities.

Learning tasks have been explored as a context of information seeking and use since the 1980s. In particular the work by Carol Kuhlthau on the information searching process (ISP) model has been fundamental in the field (see e.g. Kuhlthau, 2004). The ISP model was developed from the individual constructivist perspective where information searching is seen as a sub-process of the construction process of learning. Later the model was tested in collaborative learning contexts. For example, Hyldegård $(2006,2009)$ studied the applicability of the ISP model to the analysis of information behavior of student teams. The ISP model did not ideally serve the study of teams. The problem solving process shifted between the group and the individual perspectives. Hyldegård concluded that the task becomes a complex framework to study when teams of individuals are involved.

The process model of information behavior in assigned learning assignments proposed by Tanni \& Sormunen (2008) makes an interesting differentiation between the cognitive process of learning and the physical process of composing an epistemic artifact, such as an essay. The work on the epistemic artifact links the task-based model of information behavior in learning (see Tanni \& Sormunen, 2008) to the knowledge-building process model by Stahl (2000; see Fig. 1). The focus on the epistemic artifact encourages the analysis of, for example, how source information is used in writing texts (Sormunen, Heinström, Romu, \& Turunen, 2012; Sormunen \& Lehtiö, 2011) and how the depth of collaboration is associated with the quality of the text written (Kiili, Laurinen, Marttunen, \& Leu, 2012; Kiili, 2012). 


\section{Eero Sormunen}

The task-based and the sociocultural approaches are at times seen as mutually exclusive research paradigms. We believe that a deep understanding of information seeking and use in collaborative learning processes requires that neither individual nor social aspects are neglected. The framework for cognitive, task-based information seeking and retrieval proposed by Ingwersen and Järvelin (2005, 313-357) includes social, organizational and cultural dimensions of the (work) task context as a bridge to sociocultural research themes. The framework does not emphasize collaboration of the actors but on the other hand does not exclude it either.

\section{Related research}

Past research has seldom focused on the ways how students collaborate in group work inquiry. One exception is Kiili, Marttunen, Laurinen and Leu (2012) who studied information acquisition and meaning making processes in a pseudocontrolled setting. Student pairs of an upper secondary school conducted essay projects on a controversial topic (censorship in the internet). The subjects started by a 15 minutes' discussion about the topic, continued by searching for information for 30 minutes on the Web and ended by writing an essay during the last 45 minutes of the assignment. The authors analyzed students' behavior in two dimensions: as to whether the pairs were oriented 1) to deep or shallow processing of information contents, and 2) to work in collaboration or individually. In the cluster analysis five student pair patterns were identified:

- Co-constructors $(n=2)$ were engaged in collaboration and used considerable time (83\%) for deep processing of information (constructing meaning from sources and constructing knowledge for their essays).

- Collaborators $(n=2)$ were also engaged in collaboration but they shared time equally $(41 \%$ vs. $46 \%)$ between shallow processing (i.e. knowledge acquisition and clarification) and deep processing of information.

- Blenders $(n=6)$ shared their time equally between collaborative and individual activities. In collaboration they were mainly involved in deep processing of information (37\%).

- Individually-oriented readers $(n=4)$ used less time in collaboration (32\%) and most of it was related to shallow processing of information (25\%).

- Silent readers $(n=5)$ used very little time for collaboration $(14 \%)$ and it was equally shared between deep and shallow processing of information. (Note that by reading, researchers refer to a broad spectrum of activities: searching, assessing and reading sources, and writing a source-based text.) 


\section{Eero Sormunen}

A group of teachers made independent assessments of essays with the outcome that the average scores of group essays was higher than the scores of individually composed essays in the control group. Within the experimental group the co-constructors earned the highest scores and the silent readers were given the lowest. In the post-study questionnaire, the majority of students agreed that collaboration was especially useful in exploring different viewpoints on the issue, in evaluating usefulness of information, and in extracting main ideas from the sources.

Kuiper, Volman and Terwel (2009) made an extensive study on four teachers working with 94 5th grade students on a brochure about healthy food. The collaborative inquiry activities aimed at both the development of web literacies and content knowledge building. The groups of one school were substantially more active in collaboration, had a higher motivation to complete the project, shared more actively information within and beyond the group, and knew what everyone else was doing. In addition, learning results were assessed high in this class. The authors argue that the teacher of this class was the only one who "focused explicitly on collaborative group work and introduced herself as part of that group. She talked with the students about the ways of working together at the computer and took time to solve problems. She created extra conditions to affect this collaboration, for example by physical rearrangements in the classroom...".

In a case study by van Aalst, Fung, Li and Wong (2007) six groups of 2-3 secondary school students completed a fiveweek inquiry project. The teacher did not allocate specified roles for group members but it turned out that in the actively collaborating groups one of the members had taken on leadership status. In a similar study also from Hong Kong, Jun and Pow (2011) found that all groups showing active collaboration had a recognized leader. The reverse did not hold: some recognized leaders failed to activate other members to collaborate and had to make most of the work alone. In both case studies, actively collaborating groups were more likely to create high-quality inquiry reports. Also Pauli, Mohiyeddini, Bray, Michie, and Street (2008) found that inability to work on the actual task was a problem in groups lacking leadership.

Meyers (2010; 2011) studied the effect of group work on middle school students' information seeking, learning outcomes, and problem solving. In the field experiment, half of the 120 students (ages 13-14 years) performed two complex health-related information seeking (and problem solving) tasks in groups of threes and the other half as individuals. Data were collected by observation, screen capture, pre- and post-tests, and questionnaires (Meyers, 2011, 88-96). The analysis revealed that, on average, individuals achieved better search results than groups. There was 


\section{Eero Sormunen}

no difference in learning outcomes between groups and individuals. However, some students were high performers in one condition (e.g. individual task) but failed in the other (e.g. group task) (Meyers, 2011, 109-148). Groups seemed to favor relying on their background knowledge rather than using information sources already found, and moved quickly onto the next step of the task rather than staying to examine the issue at hand more carefully. Students perceived the need to get "everyone to agree" on a problem in group work and they tried to avoid situations where "group thinking" might lead to cognitive conflicts (Meyers, 2011, 234-240). On the other hand, students agreed in questionnaire responses that group work was "fun" and provided a great deal of affective motivation (Meyers, 2011, 241-242).

Hancock (2004) found that students who desire to work together do not necessarily learn more in a setting that fosters student interaction and collaboration. The findings by Limberg $(1997,1998)$ suggest that students' active collaboration in a group assignment leads often to more successful searching, more advanced information use and better learning outcomes but contextual and situational factors cause variation. Reviews on cooperative learning studies demonstrate convincingly that cooperative approaches enhance learning (Mitchell, Montgomery, Holder, \& Stuart, 2008; Slavin, 1991) but the outcomes depend largely on the way how group work is organized in the classroom (Gillies, 2003; Huber \& Huber, 2008).

Studies in higher education suggest that student groups can apply quite sophisticated strategies in balancing between individual and collaborative efforts. For example, Saleh and Large (2011) conducted a survey study on collaborative activities of undergraduate students in an eight-month design engineering project course. Division of labor, i.e. allocating different subtasks to individual group members, was common, so that for example, information seeking could be divided by topic or by channel. When complex tasks or information needs were encountered, other group members were used as information channels or information was searched as a group. It was also common to assess the quality of information together. For similar findings, see also Hyldegård (2009).

Past research motivates to study collaboration in information literacy instruction. At least in a pseudo-experimental setting student pairs who collaborated more actively were able to write better source-based texts than individually working students (Kiili et al., 2012). Interestingly, the students adopted quite different ways to do pair work although the controlled setting was putting on pressures to collaborate and communicate intensively (Kiili et al., 2012; Kiili, 2012). In realistic classroom assignments, the gains of collaboration have not been self-evident (Hancock, 2004; Meyers, 2011). Many factors affect student teams' collaboration intensity such as the teacher's interventions (Kuiper 


\section{Eero Sormunen}

et al., 2009), and team relations, e.g., leadership (Fu \& Pow, 2011; van Aalst et al., 2007). At higher levels of education, students seem to use more elaborated forms of cooperation and collaboration (Hyldegård, 2009; Saleh \& Large, 2011). However, past research on information literacy instruction has not focused on students' group work strategies and how they justify their strategies in a realistic classroom setting.

\section{Research questions}

Our general goal was to reveal how students actually collaborate in group work assignments used commonly in information literacy education. Our point of departure was naturalistic: the findings should illuminate students' group work strategies in a typical school context. The idea of the course came from the teachers themselves and they basically had free hands in designing and implementing the assignment as they liked. They were not instructed to apply any of the dedicated pedagogical approaches for IL instruction such as Guided Inquiry: rather they leaned on their professional views on appropriate practice of schooling. The choice of the genre, Wikipedia, as the assignment's framework can be seen as a timely approach in their professional practice.

We formulated three research questions:

1. What group work strategies do students use in different activities of a source-based writing assignment?

2. Do the selections of cooperative and collaborative strategies form systematically varying patterns across activities, and if so, how do the patterns differ?

3. How do student groups justify their group work strategies?

RQ1 requires that we identify the characterizing activities used by students in performing a collaborative assignment and the types of group work strategies applied in those activities. RQ2 focuses on the variation between groups in adopting a group work strategy and tries to categorize groups on the basis of their tendency to favor or avoid particular ways of collaboration. RQ3 aims to reveal how students reason in the use of a particular group work strategy overall or in a particular activity.

\section{Data and methods}

\section{Case courses}




\section{Eero Sormunen}

Data were collected from two eight-week courses in an upper secondary school in the city of Tampere, Finland, during the spring term of 2011. Thirty students organized into ten groups (three members in each) completed a course in Finnish literature. Twenty-eight students organized into seven groups completed a course in Finnish history: two 3member, three 4-member and two 5-member groups. The members were allocated into groups randomly by lot.

On the literature course, the task was to write an article for the Finnish edition of Wikipedia and the history course used a dedicated school wiki as the writing forum. On both courses, the assignment was designed to follow Wikipedia's conventions and requirements for authors. The student groups selected a topic for their article from a list prepared by the teacher.

On the literature course each assignment was about a classic Finnish novel. The students were required to read the novel first and then write their own literary essay before the group work started. The teams were required to write about the novel, about the author, about the reception of the novel in its time

On the history course, the teacher had prepared topics dealing with Finnish history from the Civil War to the beginning of the Winter War (1918-1939). The topics were quite extensive: The Civil War (1918), a dispute over the Finnish constitution (1918-19), economic development, the role of the left wing, the role of the right wing and foreign policy. The articles on the last four topics were intended to cover the period 1918-39. For each topic, the teacher had listed sub-topics to help students comprehend what the article should contain.

The total time reserved for the assignment was 13 days in the history class and 30 days in the literature class (including time for reading the novel and preparing a personal literary essay). On both courses the assignment was introduced, written guidelines were distributed, groups formed, and topics for the articles selected at the first meeting. The second meeting was a visit to the nearby city library. One 30-minute lesson was devoted to the library collections and services and another lesson to searching on the internet. The librarian was informed of the topics selected and had collected materials from the library collection as references for the students.

After the visit to the library, the students worked the next five (in the history course four) lessons in the computer class to search for information, to select and read sources found and to write texts for the articles under the teacher's supervision. On the history course a substitute teacher was supervising the class for two lessons instead of the regular teacher. 


\section{Eero Sormunen}

\section{Data collection}

Data collection was based on a convenience sample. We were offered a possibility to cooperate with an upper secondary school which was demonstrating Wikipedia authoring as a forum of source-based writing assignments. The school's curriculum was a direct implementation of the national curriculum for upper secondary schools. We considered that the school, and its classes, students, teachers and pedagogical practices are typical of any school in Finnish cities.

The student groups were interviewed during classroom sessions and at the end of the course. The aim of classroom interviews was to collect authentic data on what the students had achieved so far in their projects, what they were currently working on, how they had organized their work in different activities and why they had decided to work as they did. The interview at the end of the course aimed to give the student groups a chance to reflect on the whole assignment process. We asked them to describe the phases of the assignment process, how they had performed different activities, how they had collaborated or divided their work, and on what grounds they decided to do so.

Our goal was to interview student groups in the classroom at least once during each 75 minute lesson while students were working on their assignment. Four groups were interviewed three times, eleven groups four times, and two groups five times during the lessons. The average length of a classroom interview was about five minutes. In ten out of seventeen groups, all members of the group participated in the final interview; in six groups, at least one member was present; and one group did not attend the last one at all. The length of the final interviews ranged from 25 to 65 minutes, with the average about 40 minutes.

The recorded interviews were transcribed and as the interviews were undertaken in groups, the transcript described each respondent as "girl 1 group x", "boy 2 group y" and so on. As the interviewer was familiar with the students, having worked in the class and interviewed them several times, she was able to identify the students by their voices. She added the fictitious names of the respondents to the interview transcripts which made it possible to identify the answers of individual students.

\section{Data coding}

The transcripts were analyzed thematically. Boyatzis (1998: 4, 11, 16-17; 31-32) describes thematic analysis as a process of encoding qualitative information explicitly by using (a set of) codes. A theme is a pattern identified in data that, at a minimum, describes and organizes an aspect of the data and, at a maximum, interprets or explains aspects 


\section{Eero Sormunen}

of the phenomenon under study. A theme can be manifest (i.e. directly observable in data) or latent (i.e. underlying the phenomenon). A code captures the essence of thematic findings, providing a link between data and the researcher's ideas about the data. (Boyatzis, 1998: 4, 11, 16-17, 31-32.)

The qualitative data analysis method was facilitated by Atlas.ti software package. As the first step of the analysis, a subsample of four student groups was selected out of the total of seventeen, with efficient code development in mind. Of both classes, the most and the least collaborative groups were selected, based on the judgment after the first careful reading of all interviews. The maximum differentiation between groups was sought to ensure that the codes developed on the basis that the subsample captured the whole variation in the groups' means of collaboration. The groups constituting the subsample are highlighted in the findings section.

The unit of analysis was a group of students, represented by the corresponding transcripts of the classroom interviews and the end interview. In thematic analysis, codes are assigned to units, which should capture "the most basic segment, or element, of the raw data or information that can be assessed in a meaningful way regarding the phenomenon" (see ibid.: 63-65). The unit of coding comprised a student group's response to each interview question or multiple responses, where a series of questions and responses elaborated a single theme.

The point of departure of the method was the theoretical construct of activities, which was devised from research on information seeking and retrieval and collaborative writing. An activity was considered as an aspect of students' (information) behavior in the context of the collaborative writing task, focusing directly on the performance of the task proper, or, as an auxiliary process, on planning the activities proper. An initial set of codes for the activities was produced a priori and revised in the context of the raw data to ensure each code was valid and applicable. The information activities were, therefore, instrumental to the analysis of strategies of collaboration in context. A total of 11 activities and 2 meta-activities used in coding were merged to five core activities (Searching, Assessing sources, Reading, Writing, Editing) and one meta-activity (Planning) used in data analysis. Only activities that were ongoing at the time the interviews or activities that preceded the interviews were considered. The cases where the group told about the activities they will do in the future were not coded as activities since the expressed intents do not guarantee that the activity was really done as planned, e.g. in collaboration.

Coding of all interviews was conducted by the second author (primary coder). The following procedure was applied to guarantee that coding was in line with the conceptions of the whole team and gave a solid basis for joint reporting of 


\section{Eero Sormunen}

findings: The third author (test coder) coded independently the interviews of three groups after training with two groups. In these three test groups the primary coder had assigned 298 codes and the test coder assigned 267 codes. The overall consistency was 64 percent in activity codes and 51 percent in group work strategy codes. Because of the low consistency in group work strategy codes the instances of inconsistent selections $(n=38 ; 27$ by the primary and 11 by the test coder) were rated independently by the first and fourth author (evaluators) using three categories "agree", "on the borderline" and "do not agree". With the primary coder, the evaluators agreed in 20 cases, regarded five as borderline cases, and disagreed in two cases. With the test coder, they agreed in three cases, considered three as borderline cases and disagreed in five cases. Removing two codes regarded as questionable and adding three new codes assigned 'correctly' by the test coder had only a minor effect on empirical results. The value of one cell in a table $3 \times 6$ data cells changed. We concluded that the primary coder identified more relevant items for coding than the test coder, that the selected codes matched closely to the conceptions of the research team and that the inconsistencies in codes seem to affect results insignificantly.

\section{Data analysis}

The analytic method of constant comparisons was applied in the analysis of the student groups' strategies of collaboration and the ways in which they justified them. The subsample was read through and an initial set of themes was produced based on (dis)similarities in the activities. This subsample was reread through several times group-bygroup and then systematically coded for the emerging themes. The thematic data were retrieved code-by-code and each theme checked internally for consistency and externally for differences across the themes. Reading within a theme emphasized the differences in the theme; reading across the themes emphasized the similarities in each theme. The codes were split or new ones added if necessary. The codes, thus, gradually developed in contact with the data, to become more discriminating and consistent. The process was concluded when the revised codes were crystallized and stabilized. As the final step of the analysis, the codes were applied to the whole set of data. The anomalies are discussed in the findings section of this paper.

Hierarchical cluster analysis (HCA) was used to identify groups which behave similarly in group work. HCA is a useful method in finding clusters of cases which have similar measured characteristics. Hierarchical clustering algorithms start from a situation where each case (here a student group) forms a cluster and combines clusters until only one is left. Distance measures such as the Euclidean distance are used in calculating similarity of clusters and adding them 


\section{Eero Sormunen}

into the hierarchical tree structure one-by-one. The result of the analysis is typically presented as a dendogram. (Aldenderfer \& Blashfield, 1984; Kaufman \& Rousseeuw, 1990.)

To apply hierarchical cluster analysis, we interpreted each activity as a dimension (variable) in which we measured the value of group work strategy. Thus the data was presented as a table of $\mathrm{m}$ columns and $\mathrm{n}$ rows ( $\mathrm{m}=$ number of activity categories; $n=$ number of student groups). Our data on group work strategies are ordinal and thus can be ranked. The categories of group work strategy were presented as integers $0 / 1 / 2$ in ascending order of collaboration intensity. The differences between all neighboring ranks were one unit because there was no reason to give some group work strategy more weight by increasing its distance from the others. We argue that this quantification is appropriate for exploring differences in overall behavioral patterns to support our qualitative analysis. Quantification was necessary also because the SPSS software requires numeric data in the cluster analysis. The following parameters were used in the analysis:

- clustering method was between-group linkage

- distance measure was squared Euclidean distance

- the number of clusters was not specified in advance

Our data for 17 groups and six activities contained nine empty cells ( $9 \%$ of all cells) indicating that the interviews did not give clear evidence of the group work strategy applied. Fortunately, no group suffered from more than one missing datum. We decided to replace the nine empty cells by the most frequently used strategy applied by the group (for empty cells see Table 3 below).

\section{Findings}

\section{RQ1: Group work strategies in activities}

Our analysis revealed four group work strategies, which the students applied in the activities of their article projects.

The strategies were in the order of increasing collaboration: 1) delegation, 2) division, 3) pair collaboration, and 4) group collaboration. The first two strategies emphasize individual efforts and the two latter collaborative efforts. The analysis of team behaviors captured the way of working as it occurred in each activity throughout the project. Most groups agreed in the beginning to an overall plan on how to organize joint efforts. However, the overall plan could 


\section{Eero Sormunen}

change during the project due to situational factors such as lack of shared time or a team member's failure to complete agreed tasks. The performance of a single activity could split into several sessions and the group work strategy could change from session to session.

In DELEGATION strategy the responsibility for a selected activity was wholly given to an individual group member. For example, editing of the final article was assigned to one group member. SUSANNA ${ }^{1}$ /L8: "[We worked] pretty much on our own topics, but then I corrected those [texts] which we've been writing, their language ... more formal."

In DIVISION the performance of the activity was divided between group members into individually completed subtask. Often the decision was made at the beginning of the project that each member worked solely on a subtopic or a subsection of the article. A respondent elaborates division as an overall plan in the history class. HANNNELE/H1: "Everyone searches their own [topic] and then writes about their own ..." HANNA/H1: "... own topic. "In the literature class, members of one group discussed how they divided the tasks. SEPPO/L10: "We agreed that I take care of the plot, meaning that I did the plot analysis [...]" SEVERI: "Then I took care of the characters [...]" SEPPO: "Then the mielieu and..." SEVERI: "And the milieu, time and the story teller." SEPPO: "Then SEIJA took care of the definition."

The strategy was also adopted on the activity level as well. The group members might have a shared responsibility for an activity, but each member worked on it individually. SEPPO/L10: "SEIJA was away [...], and I had to do without her. And SEIJA [...] later brought a couple more sources [...]." Some groups shared ideas and information sources between group members, but still kept working on their own subtopics. ISMO/H7: "[We agreed that one can] share books, if one sees things concerning others' topics or something else, then one can share them. "

In PAIR COLLABORATION two members of the (larger) group worked together in an activity. One collaborating pair described particularly aptly the strategy in action. SOHVI/L6: "[... SOFIA sat in front of the computer and I next to it, and SOFIA wrote and both... " SOFIA: "[...] spoke". SOHVI: "So, both were suggesting all along what we should be writing next." SOFIA: "And then we were jumping backwards a little, 'that no, let's say it like that after all and let's change the word order $[\ldots]^{\prime \prime}$.

The strategy was typically a deviation from the general plan of DIVISION or GROUP COLLABORATION. The latter particularly happened in three member groups. Group $\mathrm{H} 2$, which had assigned each member a subtopic, turned

\footnotetext{
${ }^{1}$ All names are fictionous.
} 


\section{Eero Sormunen}

occasionally to pair collaboration. HILJ/H2: "We have searched on our topics, and then those two [other members of the group], they too have two topics, and they have been searching (for information) about them together. " Group L5 adopted the overall plan of GROUP COLLABORATION but was forced to provisional PAIR COLLABORATION because the third student was absent. TOINI/L5: "Well, there were only two of us present, but we worked together." [P51:8] Some groups adopted even more complex arrangements including both division of work and pair collaboration within an activity. SIIRI/L3: "SIPI took care of the scene and time [of the novel], and then I and SIMO worked on the themes and interpretations."

In GROUP COLLABORATION at least three team members worked together on the same activity. Typically it was used at least in the initiation of the project. Some groups adopted group collaboration as an overall strategy but some groups worked together only in a few activities. Group H5 explicated the first approach concisely. ILPO/H5: "In the beginning everyone was present, when we divided the tasks." Another group described group collaboration as a combined reading and writing strategy. TEEMU/L9: "Mostly in the way that one wrote and others looked from the source materials for suitable sections, and then it was revised once we got it into some kind of a shape." Sometimes groups gathered together to plan the next steps although their overall plan was to work independently on their personal themes. IIDA/H6: "In the end, I guess we talked about something." IIRIS/H6: "We discussed, about how we're going to put these (text pieces) there (in the Wiki), and at which point, we ended up deciding that we'd do that independently as well."

Table 1 shows how many of the groups mentioned the use of a particular strategy in performing an activity. For example, in the searching activity we have data on 16 groups. The interviews revealed that 2 out of 16 groups delegated, 15 divided, 4 worked as pairs and 9 worked in larger teams in searching at some points of their projects. The second last row presents dominating strategies for each activity across all groups. The groups could apply various strategies in performing an activity at different stages of the assignment process. The last row gives the average number of strategies a single group used per activity.

[Table 1 about here]

DELEGATION was not a commonly applied strategy. Planning and reading was never delegated and most of the other activities were delegated by one or two groups only. The final editing was an exception since six groups delegated the activity to one group member. The use of DIVISION strategy was particularly common in searching and writing (15 


\section{Eero Sormunen}

groups), slightly less common in planning and assessing sources (11 groups), and least likely applied in editing (6 groups). In reading it was the most popular strategy but only 11 groups mentioned explicitly if they did or did not collaborate in reading.

PAIR COLLABORATION was used more often than delegation but yet only 2-5 groups per activity reported that pair work was practiced in their group. It was the most typical in planning and the least typical in assessing sources. GROUP COLLABORATION was as popular as the division strategy in planning and assessing sources (11 groups) and even more popular than any other method in editing ( 8 vs. 6 groups). However, division was far more common than group collaboration in searching (15 vs. 9), reading (6 vs. 3) and writing (15 vs. 5 groups).

Overall, DIVISION was a dominant strategy in searching, reading and writing. DIVISION and GROUP COLLABORATION were equally popular in planning and in assessing sources. The distribution of strategies used in editing was different from other activities. The use of all group work strategies was nearly as common since 4-8 groups applied delegation, division, and pair collaboration and group collaboration. The average number of strategies applied by a group in a single activity was 1.5. The main deviations from the mean were in searching (1.9) and reading (1.1). The cooccurrences of strategies are discussed in more detail below.

\section{RQ2: Patterns of overall group work behavior}

The second research question dealt with the patterns of variation in group work behavior across activities. By comparing the patterns in adopting group work strategies for different activities, we try to assign student groups into clusters within which the variation is minimized and between which the variation is maximized. The hierarchical cluster analysis (HCA) help explore systematic patterns in the groups' overall collaborative behavior. The input data for the cluster analysis was created by assigning value " 0 " to activities where the group used strategies $A$ (delegation) or B (division) or their combination. Plain collaborative behavior - C (pair collaboration), D (group collaboration) or their combination - was given value " 2 ", and mixed behaviors (combination A-C, A-D, B-C, and B-D) the intervening value " 1 ". Thus numbers 0,1 and 2 symbolize the increased intensity of collaboration in performing an activity.

[Figure 2 about here]

The dendogram resulting from the hierarchical cluster analysis is presented in Figure 2 . The dendogram indicates that student groups can be separated into four clusters if we take the maximum distance of 10 units as a threshold. The 


\section{Eero Sormunen}

representation tells only what groups are similar in their collaborative behavior but does not show what the behaviors actually are. Table 2 presents collaboration information in the cluster structure (see column "Clusters"). The groups of Cluster 1 completed most activities working together. The groups of Cluster 2 worked in mixed mode by working partly together and partly alone in many of the activities. Cluster 3 does not shape a homogeneous representation of four groups. Group L5 matches poorly the overall pattern of the other three groups. Cluster 4 is more homogeneous and is characterized by a pattern whereby group work falls apart in reading, writing and editing if not before.

Unfortunately, the cluster structure based on mechanically calculated distances does not work optimally as a representation of activity sequences. Adding one group at a time may lead to a separation of close pairs into different clusters. Thus we introduce another clustering which is based on a subjective and intuitive interpretation of collaboration patterns across the sequence of activities (a process-oriented view). The clusters are presented in column "Adhoc clusters" of Table 4. The first cluster was named Collaborators and it consists of the same three groups as the calculated Cluster 1 . These groups completed most activities together. The second cluster is an extension of Cluster 2 and called Cooperators since the groups coordinated individual efforts in most activities from planning the work up to the stage of writing. Team members could work alone on an activity but at least kept other team members informed of personal activity. The third cluster was labeled Disjointed. The groups in this cluster started by planning the work together or departed already at this stage. Anyway, the general tendency was that the disintegration increased towards the end of the project. The last two groups were regarded as outliers but their patterns in collaborative behavior resemble those of the disjointed cluster groups.

[Table 2 about here]

\section{RQ3: Justifications for the group work strategies}

The justifications reported below capture conscious choices described by the student groups. The students also mentioned other factors that influenced their group work strategies such as fellow group members' absence because of illness or a class trip. These factors were, however, excluded from the findings as being circumstantial rather than reflecting students' conceptions of group work strategies.

The justifications concern both the student groups' overall plans as well as their strategies for individual activities. SULO/L8 explains how the group's decision to allocate each member a section of the article to write led to the division 


\section{Eero Sormunen}

of searching as well: "[The article] is made in sections anyway, that is, everyone has a section of their own. Why would you need that [extra] information? There's no point in searching for information if you have no use for it yourself."

DELEGATION was mainly used in editing. Three groups delegated also in other activities, group L4 being the most active by delegating in three activities. They found delegation beneficial in three different ways. A group member argued that delegation is a common strategy to ensure FAIR SHARE OF WORK but denied that it was the reason to delegate in their group. TAAVI/L4: "[In group work] someone gets to cop out. I don't think of TANELI as someone who cops out [...] But had this been typical group work, [...] that someone cops out, does nothing." Delegation was also justified by the SPECIAL COMPETENCE of a member. TAAVI/L4: "[... I would never have been able to upload it into Wikipedia, nor would TAIJA [...]". The person mentioned raised the third justification by saying that the activity was in his PERSONAL PREFERENCES. TANELI/L4: "[Writing to Wikipedia] was very satisfying."

DIVISION was justified with the EFFICIENCY OF THE WORK PROCESS. The theme captures various subthemes about coping with the social costs of group work. The students argued that they were able to concentrate or specialize in their individual activities. IIDA/H6 explains: “One's maybe better able to focus one's information seeking, so one doesn't have to seek anything so widely." A member of group $\mathrm{H} 7$ also argued for efficient use of time in assessing information. ILPO/H7 : "It'll take quite a lot of time, to begin looking at all the group members' texts one by one and the sources ... used in them." Group H7 pointed out that division of work was easier to schedule than group collaboration. ISABELLA/H7: "One can do some of it in school, but as there's always some of it left for spare time, then you always have to wangle those times when we could meet."

Efficiency also covered the justification of avoiding overlapping work. ILMATAR/H5: "As it's five persons in the group [...] if all start doing the same thing, maybe a lot of overlap occurs." Not having to keep an eye on the others' work was also an efficiency issue. HILDING/H2: "It was in my opinion much more efficient to do it alone, you don't have to constantly check what [...] the other does." One efficiency related explanation was the perceived lack of time to work together. Group L2 was forced to work at home because they were running out of time at school. TUIJA/L2: "[...] it was necessary to divide a bit. At first we thought we could make all of this together in the class as a group."

Some students expressed justifications related to perceived SOCIAL INCONVENIENCE in group work situations. For example, one student mentioned he did not like to negotiate about contrasting viewpoints and arguments with other group members. HILJA/H2: "It's somehow easier to focus on one's own topic than to try to fiddle around trying to fit it 


\section{Eero Sormunen}

all together as everybody has a different opinion [...]" and continued: "[In group work] time is wasted in thinking about how we're going to put it together as everyone wants to write differently." A member of group H4 argued that by dividing tasks they were getting more done and with less hassle and other distractions. HEINI/H4: "I personally like it this way, doing it independently, even if it was group work." HEIDI/H4 adds: "[Group work] usually becomes quite a hassle."

The TEACHER'S INSTRUCTIONS in the history class offered a reason for the division strategy. Each group in the history class was given a topic divided into subtopics by the teacher. IRA/H3: "Because we had been handed out those instructions, where the topics were clearly divided, it was pretty easy to [divide subtopics] as they don't even relate to each other much". Group H4 gave the FAIR SHARE OF WORK as a justification for the strategy. They pointed out that when each student was responsible for their own subtopic, free riding was avoided. HEINI/H4: "[...] then someone [often] comes as a free rider if it is group work so, this was really a good system. Everybody did just about as much." [P30:19] Another reason for the division was PERSONAL PREFERENCES. TAAVI/L4: "I thought [...] I could leave [to TAIJA] the source issues because I hate them." An avid reader in the group adopted writing a section of the article from source-materials; another member wrote on the basis of the novel itself.

PAIR COLLABORATION was justified by the QUALITY OF THE WORK PROCESS. One pair of girls in particular reflected on how they saw the benefits of collaboration in contrast to division of work. The pair argued that it was a positive aspect that they could hear each other's opinions, discuss the different viewpoints, and correct each other's mistakes. As a result they could motivate and trust each other. SOHVI/L6 explains why they were writing together: "It just felt natural that when we are both sitting here, we're talking about what would be good, and both suggesting different things. And then we correct each other, and just feel that it is good for us." SOFIA/L6 adds: "Motivation was higher as there were two of us, as the other was always supportive." It is a point of interest, that they were aware that writing together was not the quickest strategy to complete the article but they accepted the extra effort in order to achieve their quality standards. SOHVI/L6 explains: "It might have been [...] more efficient that we had agreed that you do this thing at home and then you do this, but I know we should have read that through anyway the next day [...] for your section is not good enough." SHARED RESPONSIBILITY was another reason given by the pair. SOFIA/L6 says: "As we both in principle are responsible for that text, then [we will not] just blame each other for a poor section or so." The pair explained the use of pair collaboration with FAIR SHARE OF WORK. SOFIA/L6 reflects on the group's overall 


\section{Eero Sormunen}

strategy: "We were both really happy with that and [...] that feeling didn't come when one does something and the other just sits and does nothing."

GROUP COLLABORATION was also justified with the QUALITY OF THE WORK PROCESS. The groups argued that they were getting many opinions heard. TUIJA/L2 justifies assessing information together as a group: "I find it's somehow more reassuring that we tell each other our opinions. And as everybody has their own views on what is important, we thought it would be good to do this as a group." Justifications concerning the QUALITY OF THE END-PRODUCT emphasized achieving a (better) result. SEPPO/L10 explains why the group was collaborating in searching: "We settled on [group collaboration], as we just want as many sources as possible so we'll get as good and broad idea of our book and writer as is possible." Another group (L9) justified writing and editing together to achieve a more consistent endproduct. Taking SHARED RESPONSIBILITY for the article was another reason for group collaboration. TEEMU/L9 justified writing together: "It's nevertheless a work by us all, so we don't need [...] to get this done quickly."

\section{Discussion}

The knowledge pedagogy (Scardamalia \& Bereiter, 2006) and especially the model for the collaborative knowledge building process (Stahl, 2000) give us an appropriate framework to interpret our empirical findings. The process model presented in Fig. 1 emphasizes both the individual effort to enhance one's personal understanding and the collaborative effort of knowledge building. In the latter effort, the role of collaboration in constructing the epistemic artifact (here the content of the article) becomes essential: Do students plan the contents of the article beyond listing subtopics for each team member to work on? Do they assess and read sources together to build shared understanding? Do they collaborate in writing at the level of genuine knowledge construction?

Our findings show that there is a good deal of variation in how much students worked together during the group assignment. Collaborators tended to work together in all activities (social knowledge building circle in Fig. 1). These groups had at least in principle the chance to articulate their personal beliefs to others, discuss alternatives, clarify meanings, negotiate perspectives, and formalize and objectify their shared understanding in the written article. Our data does not allow us to draw strong conclusions about the extent to which collaborative knowledge building really occurred in these groups. The interviews indicate that several students - especially those working in pairs - strove for close collaboration in their groups. However, this behavior may emphasize either shallow processing of information 


\section{Eero Sormunen}

(i.e. knowledge acquisition and clarification) or deep processing of information (i.e. meaning and knowledge construction) as in the clusters Co-constructors and Collaborators identified by Kiili et al. (2012).

Cooperators were potentially applying the principles of knowledge building model by Stahl (2000) since they worked both individually and collaboratively rather consistently across all activities. Thus they had a possibility of moving fluently between the individual and social learning circles (cf. Fig. 1) but we miss signs of collaborative knowledge building. Team members worked separately in some parts of nearly all activities. The interviews also revealed that many students emphasized the efficiency of work division and delegation in composing the article. This suggests that team members agreed to avoid engaging into shared meaning or knowledge construction but tried to coordinate individual efforts to achieve a thematically unified text required by the teacher. Cooperators' behavior shares similar features with the cluster of Blenders in the study of Kiili et al. (2012).

The groups in the Disjointed cluster either started to work collaboratively (planning, searching, assessing) and drifted apart to work individually later (reading, writing, editing) or split the work into personal projects already at the beginning. In both cases the groups did not collaborate in the sense of social knowledge building (cf. Fig. 1). Learning is limited by these groups to enhancing personal knowledge in the topic the student was working on. In the interviews some groups told that they decided to work separately on selected subtopics but planned to merge texts at the end. It turned out that they had no time to do that. These groups failed in conducting and completing their project as a cooperative effort.

Table 2 highlights a dramatic difference between the classes of history and literature. All three groups in Collaborators, and five out of six groups in Cooperators were from the literature class. At the bottom, six out of eight groups suffering from disintegration were from the history class. A likely explanation for the difference is that a substitute replaced the history teacher during her absence in the middle of the project lessons. From our data we see that this led to a situation where students in the history class received less guidance and feedback and, further, their progress was not controlled regularly. Earlier studies suggest that when the teacher is not explicitly advocating, supporting and guiding students to collaboration the student's collaboration activity remains low (cf. Kuiper et al., 2009).

The problems related to the lack of leadership in the group (Fu \& Pow, 2011; Pauli et al., 2008; van Aalst et al., 2007) did not arise as a real issue in our data. Each group had a leader who was responsible for reporting work done at some 


\section{Eero Sormunen}

points in the project. Several group members gave credit to the leader student for his or her role. In one group we could see that one member was taking on the roles of both a leader and an active worker, resulting in an unequal division of workloads.

Students' justifications in preferring either cooperative or collaborative group work strategies were quite different. Students favoring cooperation in forms of work delegation and division emphasized efficiency. By efficiency, students meant, for example, that the required texts are completed in time, or that one can personally focus on a limited task and need not care about what others are doing in their tasks. Efficiency was also involved when delegation was justified by special competences of one particular person: the activity is completed faster by an expert than a novice. Avoiding collaboration was justified also on the basis of extra effort and time required in achieving a shared understanding or opinion in a group. This seemed to be not just an efficiency issue but also a question of perceived social inconvenience of contradiction in a group. The finding is in line with Meyer's (2011, 234-240) observation that some students try to avoid possible cognitive conflicts in intensive collaboration.

It was interesting to observe that the fair share of work was presented as a justification for both cooperative and collaborative strategies. In collaboration, fairness was seen as a contribution in the collaborative activity in terms of discussion and participation. The groups favoring cooperative strategies regarded the text written by each member alone as the best guarantee in manifesting the fair share of work. The two lines of thought seem to rest on either trust or mistrust. Similarly, Limberg $(1997,1998)$ found that team members who shared positive conceptions of group work were more engaged to deep collaboration. This finding may be related to the findings that high achievers prefer working on their own (Bahar, 2003) and that they might feel contributions unequal within the group (Pauli et al., 2008).

The groups favoring collaboration were aware of the extra effort of working together but could accept the risk of lower (technical) efficiency. They emphasized shared responsibility in completing the task and the quality of the process and its outcome. Their comments indicate that individual members trusted that other group members would help them, for example, in searching or in assessing sources and improving their own texts. These groups did not see the interaction with other members socially stressful, but instead emphasized that different viewpoints help to extend and improve the contents of the article. It seems obvious, therefore, that the groups favoring collaboration had a potential to use more time for joint knowledge acquisition and clarification as well as for constructing meaning and 


\section{Eero Sormunen}

knowledge. In the experiment by Kiili et al. (2012) this happened in the actively collaborating student pairs who achieved better learning outcomes in terms of higher group essay scores. Limberg's $(1997,1998)$ qualitative study indicated a similar connection between active collaboration, more effective searching for information and better learning outcomes.

\section{Conclusions}

Our point of departure in this study was that group work assignments are commonly used in information literacy instruction. However, in our experience, the goals of group assignments were not achieved since many student groups seemed to avoid collaborating. Past research on information literacy instruction did not tell much about how students work in group assignments and how they justify their practices. We took cooperative learning and collaborative learning - and especially knowledge building pedagogy - as a general framework to motivate the discussion on the individual and social aspects of information behavior and learning. The task-based approach to information seeking and use framed our empirical work: the division of the assignment into subtasks helped analyze systematically group behaviors in different activities (subtasks) of the learning assignment. As far as we know, the task-based approach has not been applied earlier to study students' collaboration strategies in information literacy assignments.

Our findings revealed that about a half of the groups studied (Cluster Disjointed plus outliers) failed to complete the source-based writing assignment as a mutually coordinated effort. At the critical stages of reading and writing team members worked separately and the resulting article was only a compilation of loosely related texts. Students' justifications for avoiding close collaboration emphasized the efficiency of individual efforts over collaboration. In this view, the focus was on the individually produced piece of text as evidence required by the teacher rather than on the quality of the group process or the end-product as a whole.

A minority of three groups (Collaborators) worked together in most activities. They emphasized shared responsibility of the group and the quality of both the process and the end product. These groups had at least in principle a possibility to collaborative knowledge acquisition and construction (cf. Kiili et al., 2012) and to practice higher level information literacy competences (cf. Limberg, Alexandersson, Lantz-Andersson, \& Folkesson, 2008; Sundin, Francke, \& Limberg, 2011). Six other groups (Cooperators) worked both individually and as a group. They at least coordinated group efforts but probably the motivation was more to compose a coherent end-product rather than learn and construct knowledge together. 


\section{Eero Sormunen}

This work analyzed in detail students' work on subtasks in an authentic learning assignment in school. Teaching IL in a holistic way which integrates it as a natural part of students' learning process is the only way to develop long-lasting and internalized IL competences. Before pedagogics to address this is developed, however, we first need an understanding of students' existing natural information practices. This study does not only describe the variation in what students did within the framework of the same learning assignment, it also presents the students' arguments and motivations for their choices. This is an understanding we need to further develop IL education.

The teacher is the core player in the development of information literacy instruction in schools (acknowledging the essential roles of school librarians, principals and other actors in the school). In the classroom, the learning assignment is the main instrument the teacher can use to create a favorable learning environment for students to work in. Our findings call for research on different designs of learning assignments in collaborative information literacy instruction. This includes the designs to structure group work assignments to create favorable and motivating conditions for students to practice and benefit from collaboration, see Gillies (2003) and Huber \& Huber (2008). Further, we need evaluative research on pedagogical approaches to information literacy such as Guided Inquiry (Kuhlthau et al., 2007), and learning outcomes in information literacy instruction and instruments to evaluate them, see e.g. Leu, Coiro, Kulikowich, \& Cui (2012).

\section{Acknowledgements}

The study was part of the Know-Id project funded by the Academy of Finland (grants no. 132341). The authors thank the teachers of the case courses and the "Tieto haltuun" project in the City of Tampere for cooperation in data collection. We are grateful to Leeni Lehtiö and Teemu Mikkonen, who took care of the data collection during the case courses.

\section{List of references}

Bahar, M. (2003). The Effects of Motivational Styles on Group Work and Discussion-based Seminars The Effects of Motivational Styles on Group Work and Discussion-based Seminars. Scandinavian Journal of Educational Research, 47(4), 461-473.

Bereiter, C. (2002). Education and mind in the knowledge age. New York: Routledge.

Byström, K., \& Järvelin, K. (1995). Task Complexity Affects Information Seeking and Use. Information Processing \& Management, 31(2), $191-213$. 
Chu, S., Chow, K., Tse, S., \& Kuhlthau, C. C. (2008). Grade 4 Students' Development of Research Skills Through Inquiry-Based Learning Projects. School Libraries Worldwide, 14(1), 10-37.

Chu, S. K. W., Tse, S. K., \& Chow, K. (2011). Using collaborative teaching and inquiry project-based learning to help primary school students develop information literacy and information skills. Library and Information Science Research, 33(2), 132-143.

Dillenbourg, P. (1999). What do you mean by collaborative learning? In P. Dillenbourg (Ed.), Collaborativelearning: Cognitive and computational approaches (Vol. 1, pp. 1-19). Oxford: Elsevier. Retrieved from http://halshs.archives-ouvertes.fr/docs/00/19/02/40/PDF/Dillenbourg-Pierre-1999.pdf

Fu, J., \& Pow, J. (2011). Fostering Digital Literacy through Web-based Collaborative Inquiry Learning-A Case Study. Journal of Information Technology Education, 10, 57-71. Retrieved from http://oaj.unsri.ac.id/files/jite.org/documents/Vol10/JITEv10IIPp057-071Jun930.pdf

Gillies, R. M. (2003). Structuring cooperative group work in classrooms. International Journal of Educational Research, 39(1-2), 35-49. doi:10.1016/\$0883-0355(03)00072-7

Gillies, R. M. (2007). Cooperative learning : integrating theory and practice. Thousand Oaks: Sage.

Hakkarainen, K. (2009). Three generations of technology-enhanced learning. British Journal of Educational Technology, 4O(5), 879-888. doi:10.1111/j.1467-8535.2008.00873.x

Hancock, D. (2004). Cooperative learning and peer orientation effects on motivation and achievement. The Journal of Educational Research, 97(3), 159-167. Retrieved from http://heldrefpublications.metapress.com/index/71116016075n5w6n.pdf

Huber, G. L., \& Huber, A. A. (2008). Structuring group interaction to promote thinking and learning during small group learning in high school settings. In R. Gillies, A. Ashman, \& J. Terwel (Eds.), The Teacher's Role in Implementing Cooperative Learning in the Classroom (pp. 110-131). New York: Springer.

Hyldegård, J. (2006). Collaborative information behavior - exploring Kuhlthau's Information Search Process model in a group-based educational setting. Information Processing \& Management, 42(1), 276-298.

Hyldegård, J. (2009). Beyond the search process - Exploring group members' information behavior in context. Information Processing \& Management, 45(1), 142-158.

Ingwersen, P., \& Järvelin, K. (2005). The Turn: Integration of Information Seeking and Retrieval in Context. Dordrecht: Springer.

Johnson, D. W., \& Johnson, R. T. (1991). Learning together and alone. Englewood Cliffs: Prentice Hall.

Kiili, C. (2012). Online Reading as an Individual and Social Practice. Jyväskylä: University of Jyväskylä. Retrieved from http://dissertations.jyu.fi/studeduc/9789513947958.pdf

Kiili, C., Laurinen, L., Marttunen, M., \& Leu, D. (n.d.). Working on understanding during collaborative online reading, $1-57$.

Kiili, C., Laurinen, L., Marttunen, M., \& Leu, D. J. (2012). Working on Understanding During Collaborative Online Reading. Journal of Literacy Research, 44(4), 448-483. 
Kuhlthau, C.C., Maniotes, L. K., \& Caspari, A. K. (2007). Guided inquiry. Learning in the 21th century. Westport: Libraries Unlimited.

Kuhlthau, C.C. (2004). Seeking meaning : a process approach to library and information services. Westport: Libraries Unlimited.

Kuiper, E., Volman, M., \& Terwel, J. (2005). The web as an information resource in K-12 education: strategies for supporting students in searching and processing information. Review of Research in Education, 75(3), 285-328.

Kuiper, E., Volman, M., \& Terwel, J. (2009). Developing Web literacy in collaborative inquiry activities. Computers \& Education, 52(3), 668-680. doi:10.1016/j.compedu.2008.11.010

Leu, D. J., Coiro, J. L., Kulikowich, J., \& Cui, W. (2012). Using The Psychometric Characteristics Of Multiple Choice, Open Internet, And Closed (Simulated) Internet Formats To Refine The Development of Online Research and Comprehension Assessments In Science: Year Three of The ORCA Project. Literacy Research Association Conference. San Diego, CA November 30, 2012. Retrieved from $\mathrm{ftp} / / /$ conflibs.literacyresearchassociation.org/62nd_Annual_Mtg/Leu_et_al_LRAPaper_ThreeFormats. pdf

Limberg, L. (1997). Information use for learning purposes. In P. Vakkari, R. Savolainen, \& B. Dervin (Eds.), Proceedings of an international conference on Information seeking in context (pp. 275-289). London: Taylor Graham.

Limberg, L. (1998). Att söka information för att lära - En studie av samspel mellan informationssökning och lärande [in Swedish]. Borås: VALFRID.

Limberg, L. (2007). Conceptions Learning assignment as task in information seeking research. Information research, 12(4), paper colis28.

Limberg, L., Alexandersson, M., Lantz-Andersson, A., \& Folkesson, L. (2008). What Matters? Shaping Meaningful Learning through Teaching Information Literacy. Libri, 58(2), 82-91. doi:10.1515/libr.2008.010

Meyers, E.M. (2010). Losses and Gains in Collaborative Search : Insights from the Middle School Classroom. GROUP'10, November 7-12, 2010, Sanibel Island, FL USA. Retrieved from http://collab.infoseeking.org/resources/papers/MeyersUBC.pdf

Meyers, E. M. (2011). The Nature and Impact of Group Information Problem Solving in the Middle School Classroom (p. 302). Doctoral dissertation, University of Washinton.

Mitchell, M., Montgomery, H., Holder, M., \& Stuart, D. (2008). Group Investigation as a Cooperative Learning Strategy: An Integrated Analysis of the Literature. Alberta Journal of Educational Research, 54(4), 388-395. Retrieved from http://ajer.synergiesprairies.ca/ajer/index.php/ajer/article/viewArticle/652

Pauli, R., Mohiyeddini, C., Bray, D., Michie, D., \& Street, B. (2008). Individual differences in negative group work experiences in collaborative student learning. Educational Psychology, 28, 47-58. 
Roschelle, J., \& Teasley, S. (1995). The construction of shared knowledge in collaborative problem solving. In C. E. O'Malley (Ed.), Computer-Supported Collaborative Learning. (pp. 69-197). Berlin: SpringerVerlag. Retrieved from http://umdperg.pbworks.com/f/RoschelleTeasley19950CR.pdf

Saleh, N., \& Large, A. (2011). Collaborative information behaviour in undergraduate group projects: A study of engineering students. Proceedings of ASIST Annual Conference. New Orleans, LA, October 9 - 13, 2011. Retrieved from http://www.asis.org/asist2011/proceedings/submissions/35_FINAL_SUBMISSION.pdf

Scardamalia, M., \& Bereiter, C. (2006). Knowledge building: Theory, pedagogy, and technology. In I. K. Sawyer (Ed.), Cambridge Handbook of the Learning Sciences (pp. 97-118). New York: Cambridge University Press.

Sfard, A. (1998). On two metaphors for learning and the dangers of choosing just one. Educational Researcher, 27(2), 4-13.

Sharan, Y., \& Sharan, S. (1992). Expanding cooperative learning through group investigation. New York: Teachers College Press.

Slavin, R.E. (1983). Cooperative learning. New York. New York: Longman.

Slavin, R. E. (1991). Synthesis of research on cooperative learning. Educational Leadership, 48(5), 71-82.

Sormunen, E., Heinström, J., Romu, L., \& Turunen, R. (2012). A method for the analysis of information use in source- based writing. Information Research, 17(4), paper 535. Retrieved from http://informationr.net/ir/17-4/paper535.html

Sormunen, E., \& Lehtiö, L. (2011). Authoring Wikipedia articles as an information literacy assignment copy-pasting or expressing new understanding in one's own words? Information Research, 16(4). Retrieved from http://informationr.net/ir/16-4/paper503.html

Sormunen, E., Lehtiö, L., \& Heinström, J. (2011). Writing for Wikipedia as a learning task in the school's information literacy instruction. In I. Huvila, K. Holmberg, \& M. Kronqvist-Berg (Eds.), Proceedings of the International Conference of Information Science and Social Media (ISSOME) (pp. 241-248). Turku: Åbo Akademi. Retrieved from http://issome2011.library2pointoh.fi/wpcontent/uploads/2011/10/ISSOME2011-proceedings.pdf

Stahl, G. (2000). A model of collaborative knowledge-building. In B. Fishman \& S. O'Connor-Divelbiss (Eds.), Fourth International Conference of Learning Sciences (pp. 70-77). Mahwah: Erlbaum. Retrieved from http://citeseerx.ist.psu.edu/viewdoc/download?doi=10.1.1.97.8816\&rep=rep1\&type=pdf

Stahl, G. (2004). Building collaborative knowing. What we know about CSCL, 53-85. Retrieved from http://www.springerlink.com/index/V4MQ47JU17M15562.pdf

Stahl, G. (2006). Group cognition: Computer Support for Building Collaborative Knowledge (p. 500). MIT Press (author's manuscript). Retrieved from http://gerrystahl.net/mit/stahl group cognition.pdf

Stahl, G., Koschmann, T., \& Suthers, D. (2006). Computer-supported collaborative learning: An historical perspective. In R.K. Sawyer (Ed.), Cambridge handbook of the learning sciences (pp. 409-426). Cambridge: Cambridge University Press. 
Sundin, O., Francke, H., \& Limberg, L. (2011). Practicing Information Literacy in the Classroom. Dansk Biblioteksforskning, 7(2/3), 7-17.

Tanni, M., \& Sormunen, E. (2008). A critical review of research on information behavior in assigned learning tasks. Journal of Documentation, 64(6), 893-914.

Vakkari, P. (1999). Task complexity, problem structure and actions: integrating studies on information seeking and retrieval. Information Processing and Management, 35(6), 819-837.

Vakkari, P. (2003). Task-based information searching. In B. Cronin (Ed.), Annual Review of Information Science and Technology (pp. 413-464). Medford: Information Today.

van Aalst, J. van, Hing, F., May, L., \& Yan, W. (2007). Exploring information literacy in secondary schools in Hong Kong: A case study. Library \& Information Science Research, 29(4), 533-552.

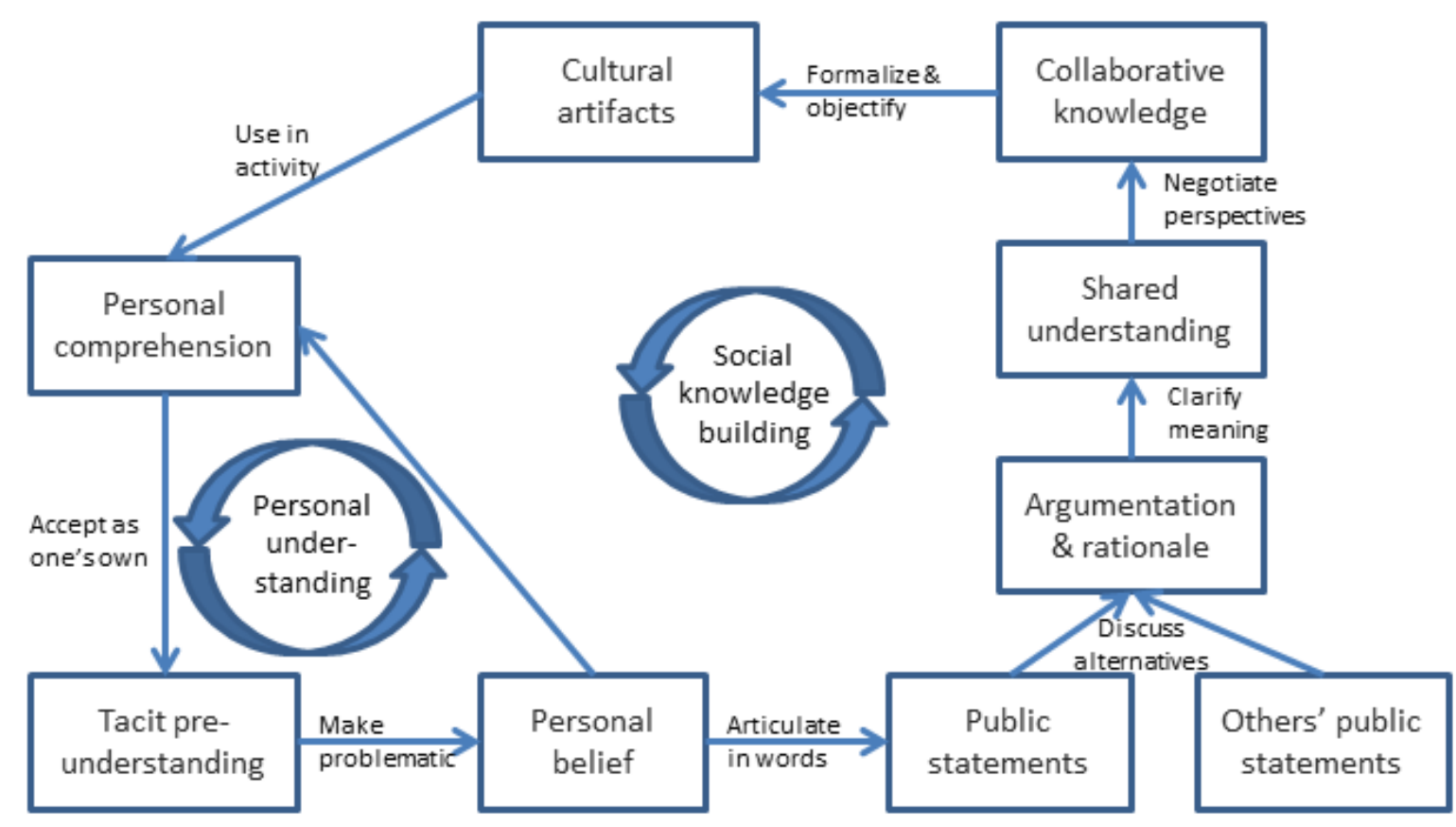

Figure 1. A diagram of knowledge-building processes (redrawn from Stahl 2000). 
Eero Sormunen

TABLE 1. The popularity of group work strategies

\begin{tabular}{|l|r|r|r|r|r|r|r|}
\hline Group work strategy & $\begin{array}{l}\text { Planning } \\
(n=17)\end{array}$ & $\begin{array}{l}\text { Searching } \\
(n=16)\end{array}$ & $\begin{array}{l}\text { Assessing } \\
\text { Sources } \\
(n=17)\end{array}$ & $\begin{array}{l}\text { Reading } \\
(n=11)\end{array}$ & $\begin{array}{l}\text { Writing } \\
(n=17)\end{array}$ & $\begin{array}{l}\text { Editing } \\
(n=15)\end{array}$ & Average \\
\hline A. Delegation & 0 & 2 & 2 & 0 & 1 & 6 & 1.8 \\
\hline B. Division & 11 & 15 & 11 & 6 & 15 & 6 & 10.7 \\
\hline C. Pair collaboration & 5 & 4 & 2 & 3 & 4 & 4 & 3.7 \\
\hline $\begin{array}{l}\text { D. Group } \\
\text { collaboration }\end{array}$ & 11 & 9 & 11 & 3 & 5 & 8 & 7.7 \\
\hline Dominating strategy & B,D & B & B, D & B & B & A, B,D & B \\
\hline \# of str per group & 1.5 & 1.9 & 1.5 & 1.1 & 1.5 & 1.5 & 1.5 \\
\hline
\end{tabular}




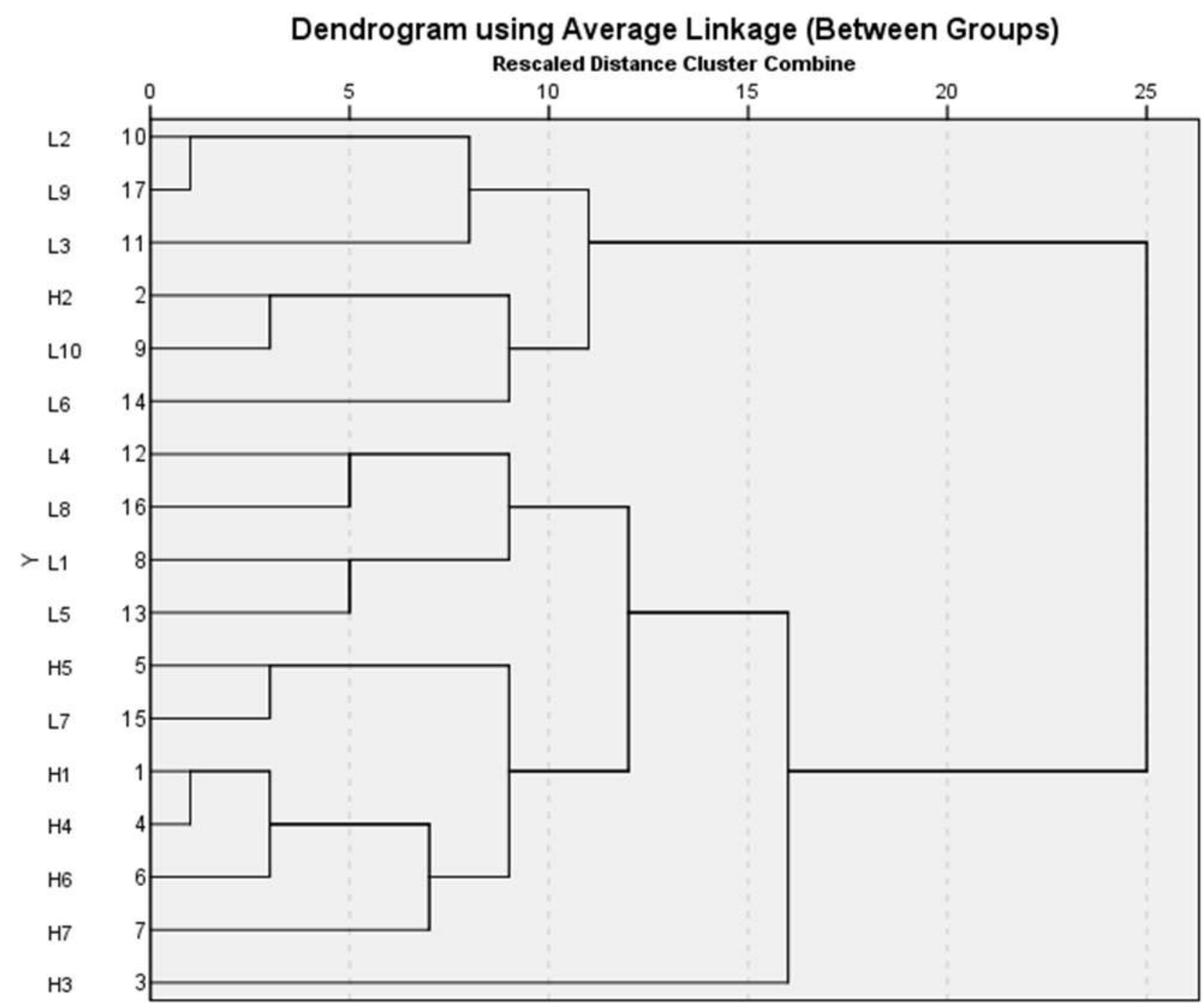

FIG 2. Dendogram of patterns in group work strategies. 
TABLE 2. Summary of group work strategies across all activities (Alone = delegation or division of work only; Together $=$ pair or group collaboration only; Both $=a$ combination of delegation $/$ division and pair/group collaboration).

\begin{tabular}{|c|c|c|c|c|c|c|c|c|}
\hline Group & Planning & Searching & Assessing & Reading & Writing & Editing & $\begin{array}{c}\text { HCA Clusters } \\
(\mathrm{d}<10)\end{array}$ & $\begin{array}{l}\text { Adhoc } \\
\text { clusters }\end{array}$ \\
\hline L2 & Together & Both & Together & Together & Together & & \multirow{3}{*}{ Cluster 1} & \multirow{3}{*}{ Collaborators } \\
\hline L9 & Together & Both & Together & Together & Together & Together & & \\
\hline L3 & Together & & Both & Together & Both & Together & & \\
\hline $\mathrm{H} 2$ & Both & Both & Both & Together & Both & Both & \multirow{3}{*}{ Cluster 2} & \multirow{6}{*}{ Cooperators } \\
\hline L10 & Both & Both & Together & Together & Both & Both & & \\
\hline $\mathrm{L6}$ & Together & Alone & Together & Both & Both & Both & & \\
\hline L4 & Both & Both & Alone & & Both & Both & \multirow{3}{*}{ Cluster 3} & \\
\hline L8 & Both & Both & Both & Alone & Both & Both & & \\
\hline L1 & Together & Both & Both & & Both & Alone & & \\
\hline L5 & Together & Both & Both & Alone & Alone & Alone & & \multirow{6}{*}{ Disjointed } \\
\hline $\mathrm{H} 5$ & Both & Alone & Both & Alone & Alone & Alone & \multirow{5}{*}{ Cluster 4} & \\
\hline L7 & Both & Alone & Together & Alone & Alone & Alone & & \\
\hline $\mathrm{H} 1$ & Alone & Both & Both & & Alone & Alone & & \\
\hline $\mathrm{H} 4$ & Alone & Both & Both & & Alone & Alone & & \\
\hline $\mathrm{H} 6$ & Alone & Both & Alone & Alone & Alone & Alone & & \\
\hline $\mathrm{H7}$ & Alone & Alone & Alone & Alone & Both & & & \multirow{2}{*}{ Outliers } \\
\hline H3 & Both & Alone & Alone & & Alone & Together & Outliers & \\
\hline
\end{tabular}

